\title{
Targeting MUC1-C reverses the cisplatin resistance of esophageal squamous cell carcinoma in vitro and in vivo
}

\author{
Yong-Qiang Zhao ${ }^{1,2}$, Ting $\mathrm{Wu}^{3}$, Li-Feng Wang ${ }^{4}$, Bo Yin ${ }^{2}$, Mo Shi ${ }^{1}$, Bin Jiang ${ }^{1}$, Xin Gong-Sun ${ }^{1}$, \\ Xue-Min Song ${ }^{1}$, Xiang-Yan Liu ${ }^{1} \wedge$ \\ ${ }^{1}$ Department of Thoracic Surgery, Shandong Provincial Hospital Affiliated to Shandong University, Jinan, China; ${ }^{2}$ Department of Cardiothoracic \\ Surgery, Jinan People's Hospital Affiliated to Shandong First Medical University, Jinan, China; ${ }^{3}$ Department of Imaging Department, Jinan People's \\ Hospital Affiliated to Shandong First Medical University, Jinan, China; ${ }^{4}$ Department of Anesthesiology, Shandong Provincial ENT Hospital \\ Affiliated to Shandong University, Shandong Provincial ENT Hospital, Jinan, China \\ Contributions: (I) Conception and design: XY Liu, YQ Zhao; (II) Administrative support: XY Liu; (III) Provision of study materials or patients: LF \\ Wang, B Yin; (IV) Collection and assembly of data: T Wu, XM Song; (V) Data analysis and interpretation: M Shi, B Jiang, XG Sun; (VI) Manuscript \\ writing: All authors; (VII) Final approval of manuscript: All authors. \\ Correspondence to: Xiang-Yan Liu. Department of Thoracic Surgery, Shandong Provincial Hospital Affiliated to Shandong University, 324 Jingwu \\ Road, Jinan 250021, China. Email: liuxiangyan1@163.com.
}

Background: The efficacy of chemotherapeutic treatment of esophageal squamous cell carcinoma (ESCC) is limited by drug resistance during. This severely compromises the long-term survival rate of patients. Therefore, reversing chemotherapy resistance in ESCC may improve the therapeutic outcome. Here, we investigated the molecular mechanism of MUC1-C, the C-terminal transmembrane subunit of MUC1 (a transmembrane heterodimer protein), and its role in the reversal of cisplatin sensitivity in ESCC cells.

Methods: We assessed the efficacy of GO-203, a cell-penetrating peptide, as a chemotherapeutic target of MUC1-C using cell proliferation, colony-forming, and transwell assays. Apoptosis was analyzed in GO203 -treated cells by flow cytometry. Tumor xenograft assay was performed in nude mice to corroborate our in vitro findings.

Results: GO-203 treatment inhibited cell proliferation and restrained the migration and invasion of cisplatin-resistant ESCC. Moreover, targeting MUC1 resulted in enhanced apoptosis in GO-203treated cells. These in vitro pro-apoptotic and anti-proliferative effects of GO-203 in combination with cisplatin were validated by in vivo models. Significantly smaller tumor volumes were observed in ESCCsxenografted nude mice treated with GO-203 in combination with cisplatin compared with mice treated with monotherapy or their control counterparts. We found that blocking MUC1-C with GO-203 significantly reversed the cisplatin resistance in ESCC via modulating Akt and ERK pathways.

Conclusions: Our findings suggest that GO-203 may hold potential as an ancillary therapeutic molecule and a chemosensitizer to improve the outcomes of cisplatin-based chemotherapy especially in patients with cisplatin-resistant ESCC.

Keywords: Esophageal squamous cell carcinoma (ESCC); MUC1-C; GO-203; Akt/ERK; cisplatin resistance

Submitted Jul 09, 2020. Accepted for publication Dec 28, 2020.

doi: $10.21037 /$ tcr-20-2495

View this article at: http://dx.doi.org/10.21037/tcr-20-2495

\footnotetext{
^ ORCID: 0000-0002-6998-1543.
} 


\section{Introduction}

Esophageal squamous cell carcinoma (ESCC) is the foremost prevalent esophageal cancer, with a total of 572,034 new cases and 508,585 deaths annually, and accounts for approximately $6.6 \%$ of all cancer-related deaths in developing countries $(1,2)$. The standard treatment of ESCCs involves surgery, chemotherapy, and postoperative chemoradiotherapy (3). However, the 5 -year survival is only approximately $20 \%$ in patients with locally advanced ESCCs (4). Cisplatin, one of the platinum-based drugs, is the most effective first-line chemotherapeutic drug for the treatment of advanced ESCC. However, the development of cisplatin resistance significantly curtails the prognosis in patients suffering from the disease $(2,5)$. Therefore, it is important to identify effective therapeutic targets and novel therapeutic molecules to improve the treatment efficacy and patient outcome.

Mucin 1 (MUC1), a membrane-bound glycoprotein (6), is aberrantly overexpressed in ESCCs and is associated with adverse outcomes (7), such as tumor proliferation, metastasis, and apoptosis (6). MUC1 is composed of an extracellular $\mathrm{N}$-terminal domain (MUC1-N) and a transmembrane C-terminal domain (MUC1-C) (8). MUC1-C has a 72 amino acid tail which can be phosphorylated by different kinases and interacts with multifarious effector molecules involved in cellular transformation (9-11). The CQC motif of MUC1-C is necessary for MUC1-C homodimerization and nucleus entry $(12,13)$. Cell-penetrating peptides, such as GO203, target the MUC1-C CQC motif, thereby blocking its activation, nuclear translocation, and downstream effects (13).

Cisplatin is a genotoxic agent that induces DNA damage, cell cycle arrest, and ultimately leads to apoptosis in many cancers (14). The Akt and ERK pathways are involved in various oncogenic processes, such as cell proliferation, migration, invasion, and apoptosis (15-17), and may interact with MUC1-C. Studies have shown that blocking MUC1-C function is effective in reversing the drug-resistance observed in cisplatin-based chemotherapy in multiple cancer cells, such as non-small cell lung cancer, ovarian cancer (18), and gastric cancer cells (19). However, whether GO-203mediated reversal of the cisplatin resistance in patients with ESCC could improve patient prognosis, remains to be elucidated. In this study, we have demonstrated that the GO-203 treatment can significantly reverse the cisplatin resistance in ESCCs by modulating the Akt and ERK pathways.

We present the following article in accordance with the
ARRIVE reporting checklist (available at http://dx.doi. org/10.21037/tcr-20-2495).

\section{Methods}

\section{Ethical statement}

This study was carried out in strict accordance with the recommendations by the Guide for the Chinese Ethics Review Committees. The protocol was approved by the Ethics Committee of Shandong Provincial Hospital Affiliated to Shandong University, and the committee's reference number is LCYJ:NO.2019-164. Animal experiments were performed under a project license (license number No. 2019-015) according to the Guidelines for the Care and Use of Laboratory Animals. All animal experiments were approved by the Animal Policy and Welfare Committee under of Shandong Provincial Hospital Affiliated to Shandong University granted by the Veterinäramt des Kantons Zürich, Switzerland, in compliance with the Swiss Animal Protection Act (TSchG) and the Swiss Animal Protection Ordinance (TSchV).

\section{Cell lines and culture}

Human Eca109 cells were procured from the Shanghai Institutes for Biological Sciences, Chinese Academy of Sciences (Shanghai, China). Cell lines resistant to cisplatin (cDDP) were generated from Eca109 cells as described previously (20). Cells were tested for mycoplasma using MycAwayTM-Color One-Step Mycoplasma Detection Kit from the Yeasen Biotech Co., Ltd. (Shanghai, China). The cells were grown in RPMI-1640 medium supplemented with $1 \% \mathrm{~L}$-glutamine, $1 \%$ penicillin/streptomycin, and $10 \%$ fetal bovine serum (BI, Kibbutz Beit Haemek, Israel), and maintained at $37.0{ }^{\circ} \mathrm{C}$ in a humidified incubator with $5 \% \mathrm{CO}_{2}$. A total of $5 \mu \mathrm{M}$ of cisplatin was added to Eca109 cells and the surviving cells were harvested. Subsequently, the cells were sub-cultured in the presence of cisplatin to maintain the resistance. All experiments were performed in triplicates.

\section{Colony formation assays}

Briefly, 600 cells/well were seeded in 6-well plates and cultured overnight. The following day, the cells were treated with (I) complete culture medium (control), (II) $10 \mu \mathrm{M} \mathrm{GO-}$ 203 (NJpeptide, Nanjing, China) alone, (III) $25 \mu \mathrm{M}$ cisplatin 
alone, and (IV) a combination of $10 \mu \mathrm{M}$ GO-203 and $25 \mu \mathrm{M}$ cisplatin. The media was changed every 2 days. The cells were maintained for 10 days at $37.0{ }^{\circ} \mathrm{C}$ in a humidified incubator with $5 \% \mathrm{CO}_{2}$ following which the colonies were stained with crystal violet and those with $\geq 50$ cells were considered as surviving colonies. The colony-forming efficiency was calculated by dividing the average number of colonies/well by the number of cells plated/well.

\section{Cell Counting Kit-8 (CCK-8) assay}

Cell proliferation was detected utilizing CCK-8 (Dojindo, Kumamoto, Japan). The logarithmically growing Eca109/ cDDP cells were treated with complete culture medium (control), $10 \mu \mathrm{M}$ GO-203, $25 \mu \mathrm{M}$ cisplatin or $10 \mu \mathrm{M}$ GO203 and $25 \mu \mathrm{M}$ cisplatin for 3 days, and then seeded at $5 \times 10^{3}$ cells/well (96-well plate). After 24,48 and $72 \mathrm{~h}$, $O D$ values were measured. Subsequently, these cells were incubated with CCK-8 reagent for $1 \mathrm{~h}$ at $37^{\circ} \mathrm{C}$. The absorbance was measured at $450 \mathrm{~nm}$ using Thermo Scientific Varioskan Flash microplate reader (Thermo Fisher Scientific, Vantaa, Finland).

\section{Wound-healing assay}

The logarithmically growing Eca109/cDDP cells were cultured in presence of complete culture medium (control), $10 \mu \mathrm{M}$ GO-203, $25 \mu \mathrm{M}$ cisplatin or $10 \mu \mathrm{M}$ GO-203 and $25 \mu \mathrm{M}$ cisplatin in 6-well plates until they reached $95 \%$ confluence. A straight "wound" was made by scratching the cells with a sterile plastic pipette tip. Subsequently, the cells were cultured in FBS-free medium and monitored for 'wound' gap closure at 12 and $24 \mathrm{~h}$, and cell migration was analyzed by microscopy utilizing Image software $(\mathrm{NIH}$, Bethesda, MD, USA). The migration rate was calculated utilizing the following formula:

$$
\begin{aligned}
& \% \text { Migration rate }= \\
& \frac{\text { The area of the initial wound }- \text { The area of wound after } 12 h / 24 h}{\text { The area of the initial wound }} \times 100 \%
\end{aligned}
$$

\section{Cell migration and invasion assays}

For both migration and invasion assays, the cells were cultured in FBS-free medium for $12 \mathrm{~h}$. Subsequently, the cells were treated with complete culture medium (control), $10 \mu \mathrm{M}$ GO-203, $25 \mu \mathrm{M}$ cisplatin or $10 \mu \mathrm{M}$ GO203 and $25 \mu \mathrm{M}$ cisplatin for 3 days. Uncoated transwells were used in migration assay, while in the invasion assay,
Matrigel (1:4; BD Bioscience) was precoated on the upper surface of the transwells. Serum starved cells were seeded in the upper chamber of the transwell plates $(8 \mu \mathrm{m}$ pore size polycarbonate membrane; Merck KGaA, Darmstadt, Germany) in FBS-free medium, while the complete medium was added in the low chamber. The migration assay plates were incubated for $24 \mathrm{~h}$ and the invasion assay plates for $48 \mathrm{~h}$. Next, the cells on the lower surface of the membranes were stained by hematoxylin. The cell numbers were calculated from at least three independent visual fields under the microscope.

\section{Protein extraction and Western blotting}

As described by Xin et al. (21), proteins were extracted from the cell line and tissue samples and harvested using RIPA buffer (Beyotime Institute of Biotechnology). Total protein concentration was determined using Pierce BCA Protein Assay Kit (Thermo Fisher Scientific, Waltham, MA, USA). An equal amount of protein $(30 \mu \mathrm{g})$ from each sample was separated on a $10 \%$ SDS-PAGE and transferred onto the PVDF membrane (EMD Millipore, Billerica, MA, USA). Nonspecific binding was blocked with $10 \%$ nonfat dry milk at room temperature for $1 \mathrm{~h}$. The membranes were incubated overnight with primary antibodies. The next day, following washing with the buffer, the membrane was incubated with secondary antibody conjugated with horseradish peroxidase anti-mouse/rabbit immunoglobulin G (Boster Biological Technology Co., Ltd., Pleasanton, CA, USA). Finally, the target bands were visualized and quantitatively detected by an enhanced chemiluminescence detection system (Amersham imager 600; General Electric, Fairfield, CT, USA). The following antibodies used in this study: anti-Akt $(1: 1,000)$ and anti-p-Akt $(1: 1,000$; Omimabs, Alhambra, CA, USA); anti-ERK $(1: 1,000)$ and anti-p-ERK (1:1,000; Omimabs, Alhambra, CA, USA); Bcl2 (1:1,000; Abcam, Cambridge, MA, USA) and anti-Bax (1:1,000; Proteintech, Chicago, IL, USA); glyceraldehyde 3-phosphate dehydrogenase (GAPDH) $(1: 1,000)$ was used as the loading control.

\section{Apoptosis analysis}

The cells were analyzed by the P-phycoerythrin (PE) Annexin-V Apoptosis Detection Kit I with 7-aminoactinomycin D (7-AAD; BD Biosciences, San Jose, CA, USA), according to the manufacturer's instructions. Cells treated with pure culture media (control), $10 \mu \mathrm{M}$ 
GO-203, $25 \mu \mathrm{M}$ cisplatin or $10 \mu \mathrm{M}$ GO-203 and $25 \mu \mathrm{M}$ cisplatin in combination were harvested by trypsinization and resuspended in $1 \mathrm{X}$ binding buffer. This was followed by double incubation with $\mathrm{PE}$ and 7-AAD for $15 \mathrm{~min}$. Subsequently, the samples were subjected to flow cytometry and the data were analyzed by FlowJo software (Tree Star Inc., Ashland, OR, USA).

\section{ESCC tumor xenograft}

A total of $1 \times 10^{7}$ Eca109/cDDP cells were injected subcutaneously into the flank region of 6-8 weeks old female BALB/c nude mice. Tumor size was measured with calipers every 2 days. Tumor volumes were calculated by using the formula:

$$
V(\text { volume })=\text { Length } \times(\text { Width })^{2} / 2
$$

When tumors reached $\sim 150 \mathrm{~mm}^{3}$, the mice were divided into four groups of five mice each, and treated with (I) phosphate-buffered saline (PBS; control vehicle), (II) GO-203 (15 mg/kg) alone, (III) cisplatin $(15 \mathrm{mg} / \mathrm{kg})$ alone, and (IV) $15 \mathrm{mg} / \mathrm{kg}$ cisplatin and $15 \mathrm{mg} / \mathrm{kg}$ GO203 administered intraperitoneally daily. Tumor sizes were measured every 4 days, the animals were sacrificed after 20 days and tumors were resected and weighed; $\mathrm{L}$ and $\mathrm{W}$ represent the largest and smallest diameters of the tumor, respectively.

\section{Statistical analysis}

SPSS 20.0 (IBM Corp., Armonk, NY, USA) was utilized to form the database for statistical analysis. The quantitative data were expressed as mean \pm standard deviation. For different treatment groups, a two-tailed Student's $t$-test and one-way analysis of variance (ANOVA) were performed. The relationship of function between GO-203 and cisplatin in cDDP was calculated by correlation analysis. Results with $\mathrm{P}<0.05$ were considered statistically significant.

\section{Results}

\section{Blocking MUC1-C reversed the cisplatin resistance in ESCC}

We developed a cisplatin-resistant ESCC cell line (Eca109/ cDDP) from Eca109 as described previously (21), Our results from the MTT assay following $48 \mathrm{~h}$ of cisplatin treatment showed a significantly higher $\mathrm{IC}_{50}$ value for Eca109/
$\operatorname{cDDP}(26.57 \pm 0.29 \mu \mathrm{M})$ than for Eca109 $(6.02 \pm 0.21 \mu \mathrm{M})$. These results confirmed that Eca109/cDDP cells were cisplatin-resistant. However, when these cells were subjected to the combined treatment of GO-203 + cisplatin, the $\mathrm{IC}_{50}$ value $(9.89 \pm 0.22 \mu \mathrm{M})$ was closer to that for the parent Eca109 cells, indicating that blocking MUC1-C could significantly reverse the cisplatin resistance of Eca109/cDDP cells.

\section{Targeting MUC1-C inbibited the proliferation of ESCCs}

Inhibition of MUC1-C expression in ESCCs following GO-203 treatment has been reported previously (16). Studies have shown that targeting MUC1-C could reverse the cisplatin resistance in many malignant tumors, such as ovarian cancer and breast cancer (18). Our results from the colony formation assay showed that cell proliferation was suppressed in Eca109/cDDP cells treated with cisplatin + GO-203, compared to the cells treated with cisplatin alone or with pure culture media (Figure 1A,B). Similar results were obtained from the CCK- 8 assay, indicating that GO203 could inhibit the proliferation of ESCCs (Figure 1C).

\section{Targeting MUC1-C restrained the migration and invasion of ESCCs}

We performed wound-healing and transwell assays to evaluate the migration and invasive abilities of Eca109/ cDDP cells. Wound closure was slower in Eca109/cDDP cells treated with cisplatin + GO-203, compared to cells treated with cisplatin alone, GO-203 alone, or the complete culture medium (control) (Figure 2A,B,C). Similarly, our results from the transwell assay showed that a significantly lower number of Eca109/cDDP cells treated with cisplatin + GO-203 crossed the transwell membrane than cells treated under other conditions (Figure 2D,E,F). These results suggested that targeting MUC1-C by GO-203 could be a reliable strategy to restrain migration and invasion in cisplatin-resistant ESSCs.

\section{Effects of targeting MUC1-C on signaling pathways in Eca109/cDDP cells}

MUC1 is overexpressed in ESCCs, and blocking MUC1-C can inhibit the proliferation and metabolism of ESCC tumors $(16,22)$. To assess the effects of targeting MUC1-C on signaling pathways in Eca109/cDDP cells, we treated the cells with GO-203 alone, cisplatin alone, cisplatin + GO- 

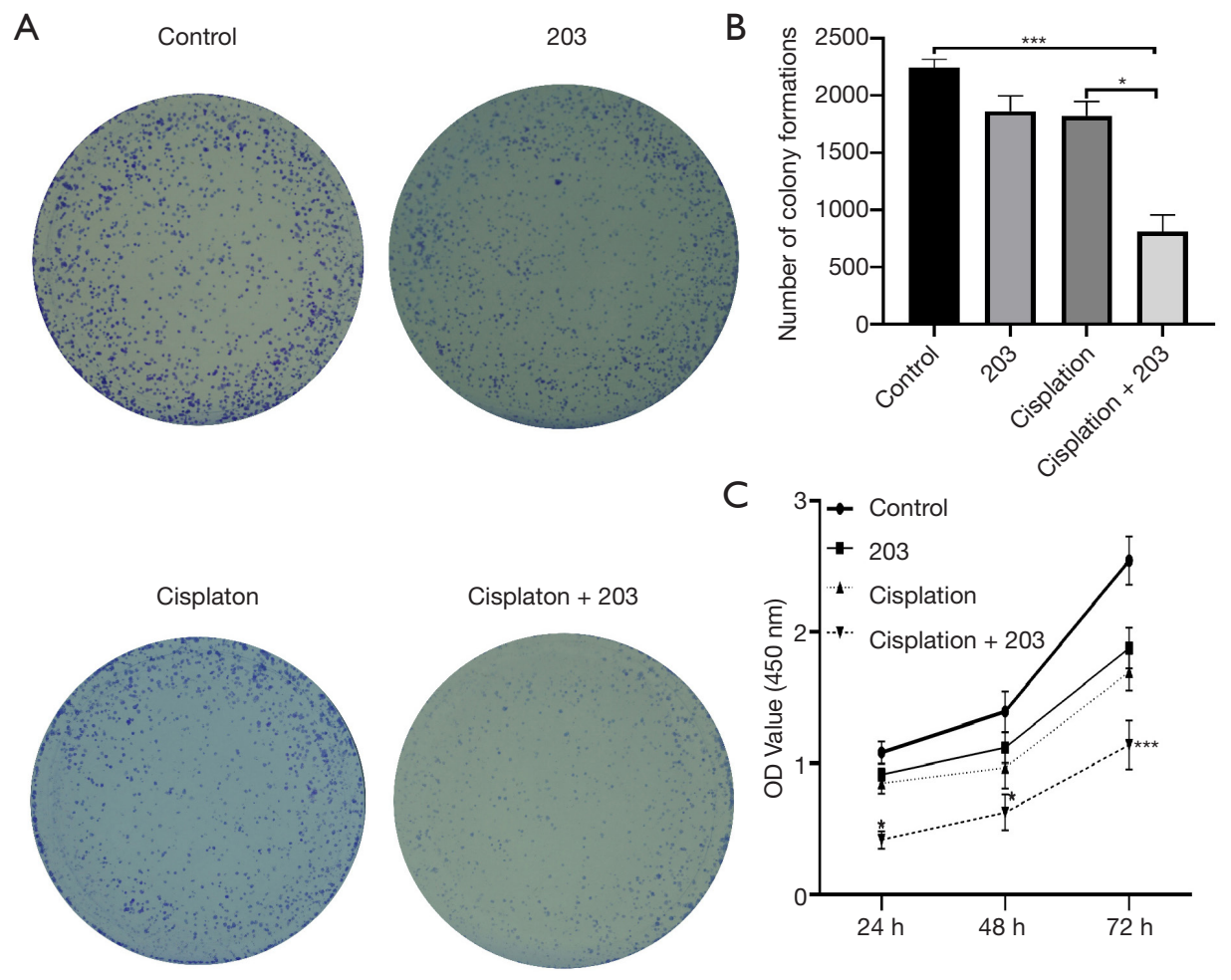

Figure 1 Targeting MUC1-C reverses cisplatin resistance in ESCC reflected in inhibiting proliferation. (A) The Eca109/cDDP cells (600 cells/well) were treated with $25 \mu \mathrm{M}$ cisplatin, $10 \mu \mathrm{M}$ GO-203, cisplatin + GO-203, or complete medium (control). After $10 \mathrm{~d}$, the cells were stained with crystal violet. (B) Colony formation (>50 cells) rates are expressed as the mean \pm SD of three replicates. (C) The Eca109/ cDDP cells were treated with $25 \mu \mathrm{M}$ cisplatin, $10 \mu \mathrm{M}$ GO-203, cisplatin + GO-203, or complete medium (control) for 3 days, and then seeded at $5 \times 10^{3}$ cells/well (96-well plate). OD values were measured after 24, 48, and $72 \mathrm{~h}$. The results are expressed as the mean $\pm \mathrm{SD}$. $\left({ }^{*}, \mathrm{P}<0.05\right.$; $\left.{ }^{* * *}, \mathrm{P}<0.001\right)$. Control: the Eca109/cDDP cells treated with pure culture media; GO-203: a cell-penetrating peptide. ESCC, esophageal squamous cell carcinoma; SD, standard deviation.

203, or complete culture medium (control). Subsequently, treated cells were subjected to western blot to analyze the expression of Akt and ERK signaling molecules. Our results revealed that treatment with GO-203 + cisplatin significantly inhibited the phosphorylation of Akt and ERK in Eca109/cDDP cells compared to the cells treated with cisplatin alone or control cells (Figure 3A,B,C). These results showed that targeting MUC1-C could compromise the Akt and ERK-mediated signaling pathways in ESCC cells.

\section{Targeting MUC1-C promoted apoptosis of ESCC cells}

Next, we examined whether the inhibition of proliferation mediated by targeting MUC1-C was a result of enhanced apoptosis in GO-203-treated cells. Our results showed that a significantly higher number of GO-203 treated
Eca109/cDDP cells underwent apoptosis than cells treated with cisplatin or GO-203 alone, or the control cells (Figure $4 A, B$ ). Western blot analysis showed that targeting MUC1-C significantly increased the levels of pro-apoptotic Bax protein and suppressed the expression of anti-apoptotic Bcl-2 protein (Figure 4C,D,E). Based on these results, we concluded that targeting MUC1-C promoted apoptosis of Eca109/cDDP cells.

\section{Targeting MUC1-C inbibited the growth of ESCC xenografts}

We established tumor xenografts in nude mice, treated them with cisplatin or GO-203 monotherapy, or cisplatin + GO203 combination therapy, and monitored the tumor growth. Our results showed that the average volume of tumors decreased significantly in mice treated with the combination 
A
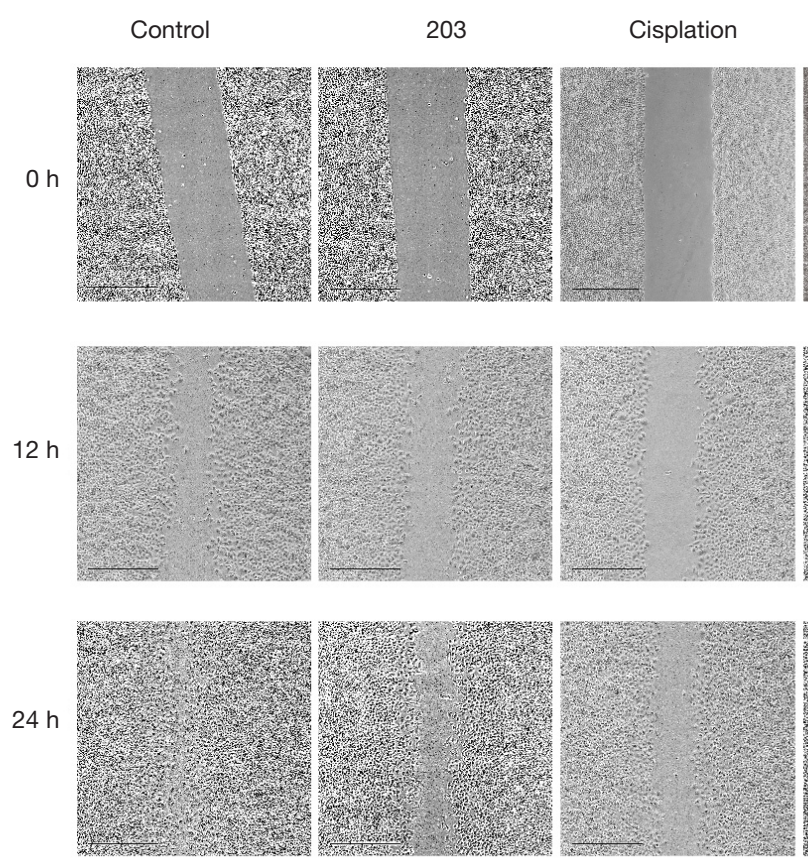

D
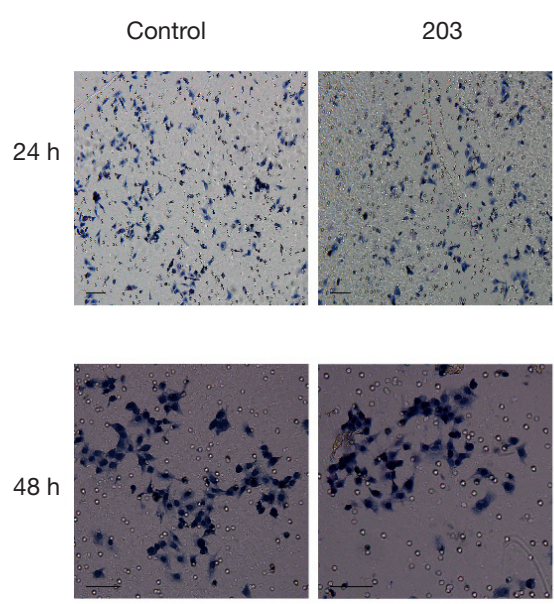
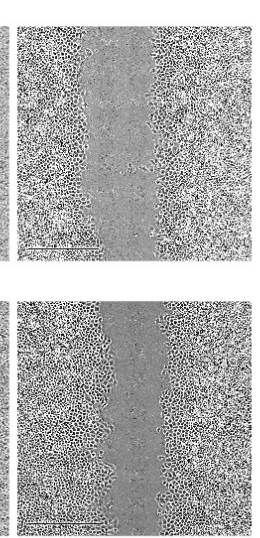

Cisplation +203

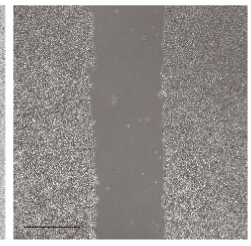

C
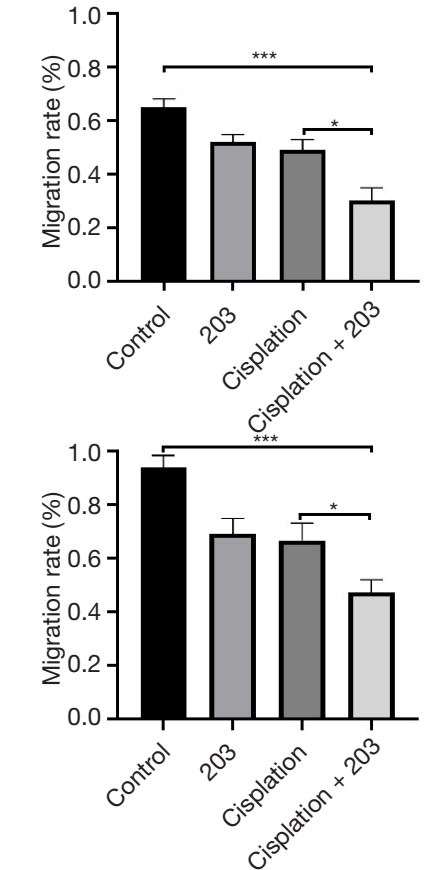

E

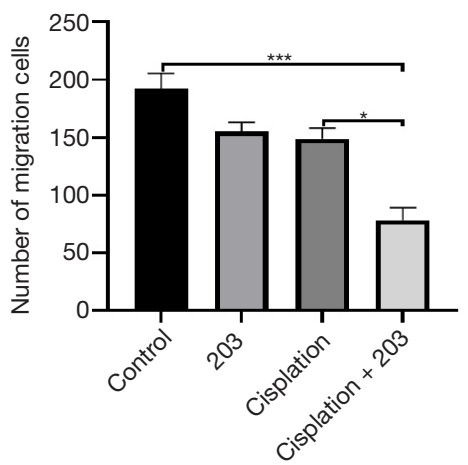

$\mathrm{F}$

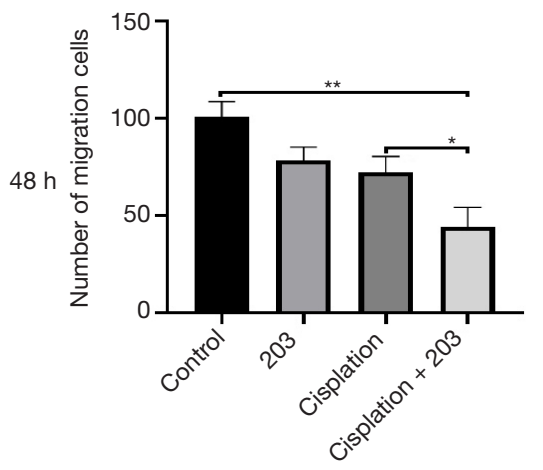

Figure 2 Targeting MUC1-C in cisplatin-resistant cells restrains migration and invasion. (A) The Eca109/cDDP cells were treated with $25 \mu \mathrm{M}$ cisplatin, $10 \mu \mathrm{M}$ GO-203, cisplatin + GO-203, or complete medium (control) and scratched to mimic a "wound". Cells were visualized by light microscopy $(\times 100)$; scale bar, $100 \mu \mathrm{m}$. (B,C) Three arbitrary visual fields were selected to count the migration rate of the cells at 12 and $24 \mathrm{~h}$ respectively. ( ${ }^{*}, \mathrm{P}<0.05 ;{ }^{* * *}, \mathrm{P}<0.001$ ). (D) $5 \times 10^{5}$ cells/well were seeded in the upper chamber of 24 -well transwell plates. The numbers of cells on the lower surface were fixed and stained after 24 or $48 \mathrm{~h}$. And the cells on the lower surface of the membranes were stained by hematoxylin. The scale bar, $20 \mu \mathrm{m}$. (E,F) The cell numbers represent the mean \pm SD of three independent experiments at 24 and 48 h respectively. $\left({ }^{*}, \mathrm{P}<0.05 ;{ }^{* *}, \mathrm{P}<0.01 ;{ }^{* * *}, \mathrm{P}<0.001\right)$. Control: the Eca109/cDDP cells treated with pure culture media; GO-203: a cellpenetrating peptide. 

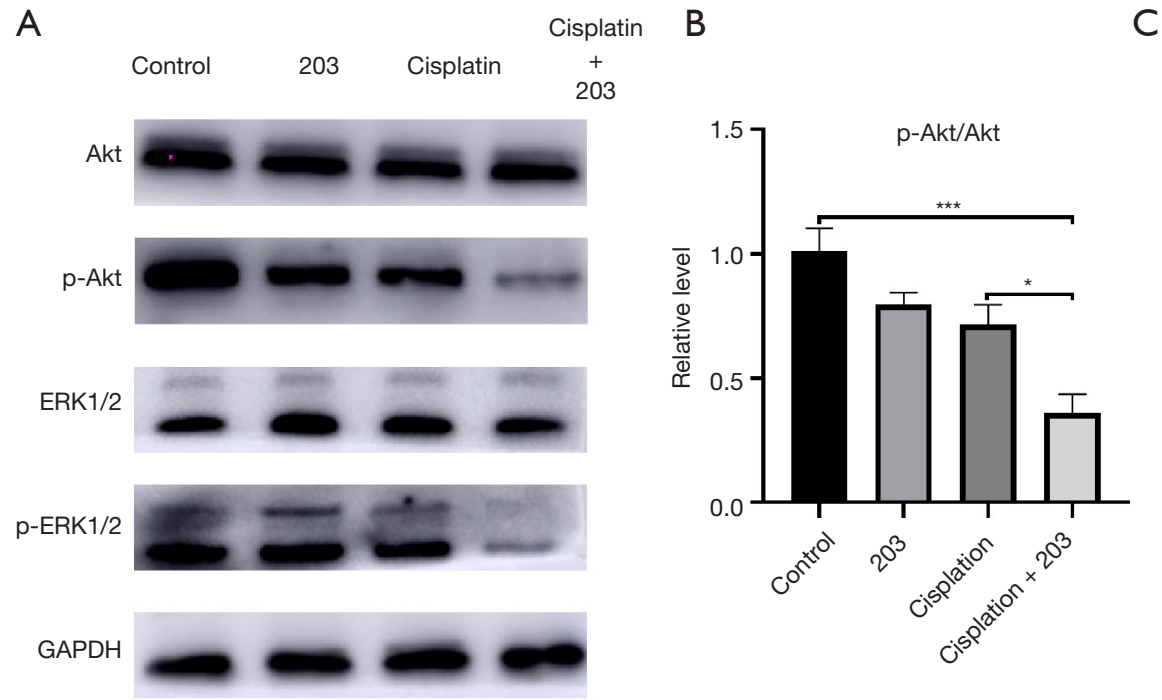

$\mathrm{C}$
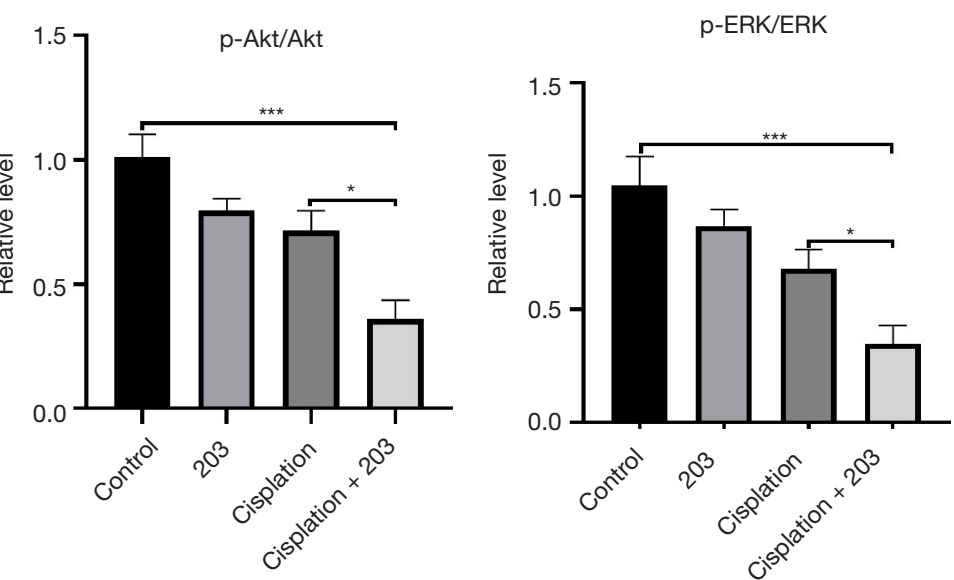

Figure 3 Effects of targeting MUC1-C on signaling pathways in Eca109/cDDP cells. (A) Eca109/cDDP cells treated with $25 \mu M$ cisplatin, $10 \mu \mathrm{M}$ GO-203, cisplatin + GO-203, or complete medium (control) for 3 days, and total protein was extracted from each experimental group. The protein samples were immunoblotted and detected with indicated antibodies against p-Akt, Akt, p-ERK, and ERK. (B,C) The detected proteins were normalized to GAPDH. $\left({ }^{*}, \mathrm{P}<0.05\right.$; *** $\left.\mathrm{P}<0.001\right)$. Control: the Eca109/cDDP cells treated with pure culture media; GO-203: a cell-penetrating peptide; p-Akt/AKT: the ratio of the p-Akt gray value to the AKT gray value; p-ERK/ERK: the ratio of the p-ERK gray value to the ERK gray value. GAPDH, glyceraldehyde 3-phosphate dehydrogenase.

therapy than either of the monotherapies or the control group (Figure $5 A, B)$. Also, the tumors from the combination therapy group presented lower weights (Figure $5 C$ ), as well as a slower growth rate (Figure 5D). In contrast, treatment with physiological saline had little or no effect (Figure $5 A, B)$. Collectively, these results suggested that GO-203 may hold potentials as a novel ancillary drug for future cancer chemotherapy of ESCCs.

\section{Discussion}

ESCC has high incidence rate and mortality. Surgical resection remains the primary choice for the treatment of early-stage and localized ESCCs (23). However, ESCCs are highly metastatic and have a poor prognosis $(24,25)$. Adjuvant chemotherapy with platinum compounds, such as cisplatin, is the first-line treatment besides surgery. However, the development of cisplatin resistance during chemotherapy poses a major challenge in the clinical management of ESCCs (23). An increasing number of studies have shown that more than $90 \%$ of cancerrelated deaths are associated with the development of chemotherapy resistance (26). Thus, there is an urgent need to identify molecules and compounds, which could reverse the cisplatin-sensitivity in ESCCs and be developed for the efficient clinical management of ESCCs.

MUC1 is overexpressed in ESCCs (23) and is associated with proliferation and tumorigenicity (27). MUC1-C has multiple phosphorylation sites and interacts with various molecules involved in neoplasia. It has been shown earlier that enhanced MUC1-C expression has a positive correlation with the growth, metastasis, and other characteristics of ESCC cells (21). GO-203 binds to the CQC motif of MUC1-C and inhibit its functions (28). Earlier studies have shown that blocking the function of MUC1-C is effective in reversing the sensitivity of cisplatin-based chemotherapy in cancers of the ovary (18), stomach (19), and prostate (29), as well as in non-small cell lung cancer and a certain hematologic malignancy $(30,31)$. However, whether it could improve ESCC prognosis or influence outcomes in patients receiving chemotherapy, remained unclear.

To explore the effects of blocking MUC1-C on the selfrenewal of cisplatin-resistant ESCC cells, we developed a cisplatin-resistant ESCC model using Eca109/CDDP cells as previously described (20). Our preliminary results showed that targeting MUC1-C in Eca109/CDDP enhanced the cytotoxicity and anti-proliferative effects of cisplatin on these cells. However, the underlying mechanism of the 
A
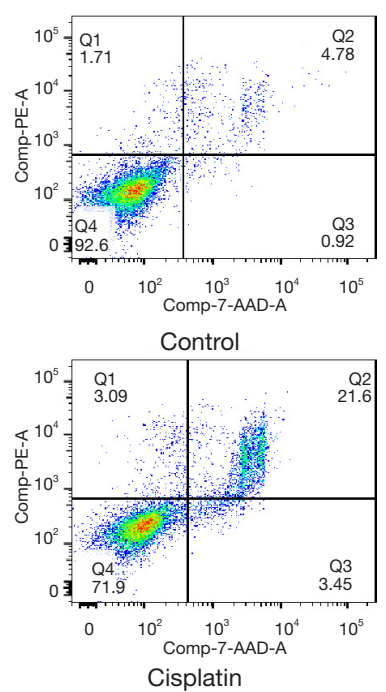

C

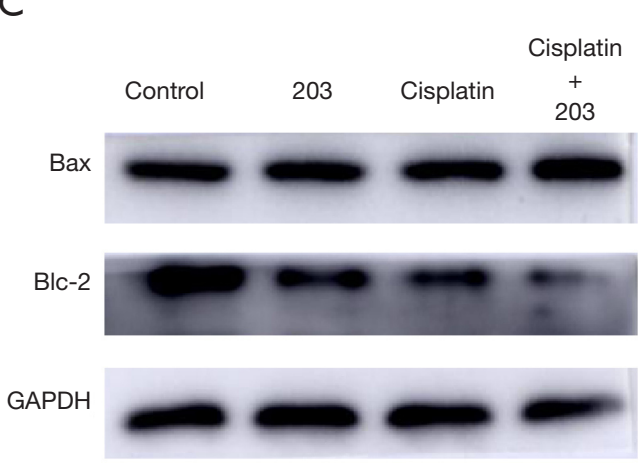

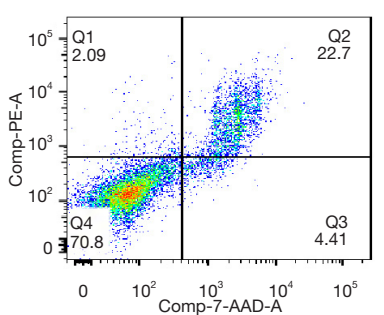

203

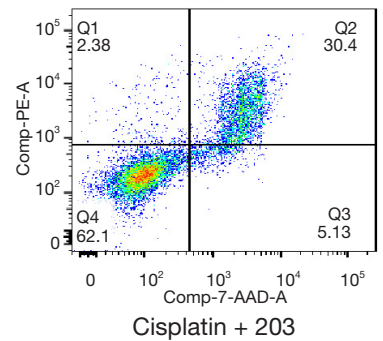

Cisplatin +203
B

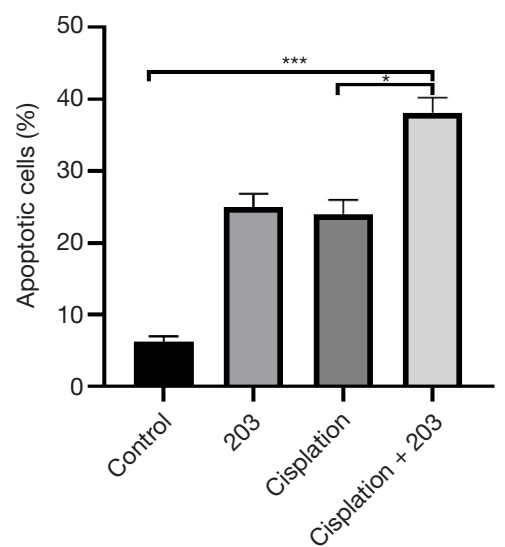

$\mathrm{E}$

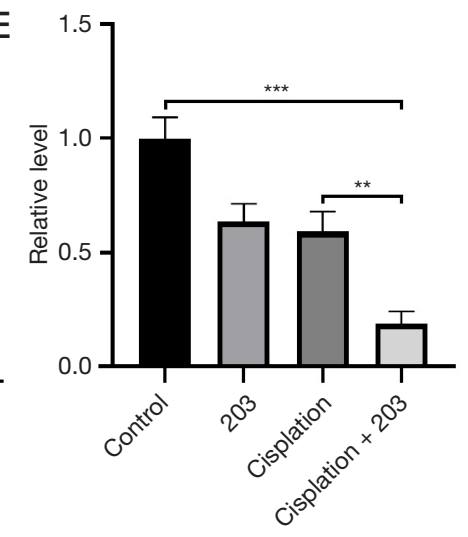

Figure 4 Targeting MUC1-C promoted apoptosis in cisplatin-resistant ESCC cells. (A) Cells were treated with $25 \mu \mathrm{M}$ cisplatin, $10 \mu M$ GO203, cisplatin + GO-203, or complete medium (control) for 4 days, followed by incubation with PE/7-AAD and analyzed by flow cytometry. The percentage of $\mathrm{PE}$ and/or 7-AAD positive cells is included in the panels. (B) The apoptosis-related factors (Bax and Bcl-2) were detected by western blotting. (C,D) Apoptosis-related factors were normalized quantitatively to GAPDH expression. (E) The results are expressed as the percentage (mean $\pm \mathrm{SD}$ of three independent experiments) of apoptotic/necrotic cells. The average values mean $\pm \mathrm{SD}$ were calculated from three independent experiments. $\left({ }^{*}, \mathrm{P}<0.05 ;{ }^{* *}, \mathrm{P}<0.01 ;{ }^{* *}, \mathrm{P}<0.001\right)$. Control: the Eca109/cDDP cells treated with pure culture media; GO-203: a cell-penetrating peptide. ESCC, esophageal squamous cell carcinoma; GAPDH, glyceraldehyde 3-phosphate dehydrogenase; $\mathrm{SD}$, standard deviation.

observed anti-proliferative effect remained unknown. The Akt and ERK signaling pathways are well-known to regulate the cell cycle, growth, cellular proliferation, protein synthesis, survival, and glucose metabolism (32-34). Several studies have shown that the Akt and ERK signaling pathways are activated during the progression of ESCC $(35,36)$. Our results from the present study indicate that targeting MUC1-C by GO-203 could significantly inhibit the proliferation, and induce apoptosis of Eca109/CDDP cells. Our results showed that treating Eca109/cDDP cells with a combination of GO-203 + cisplatin significantly inhibited the phosphorylation of Akt and ERK and their subsequent activation. These results demonstrated that targeting MUC1-C could reverse the cisplatin resistance in Eca109/CDDP cells through the Akt/ERK signaling pathways. Further, our results showed that the combination treatment with GO-203 and cisplatin induced apoptosis of these cells. Flow cytometric apoptosis assay showed 
A

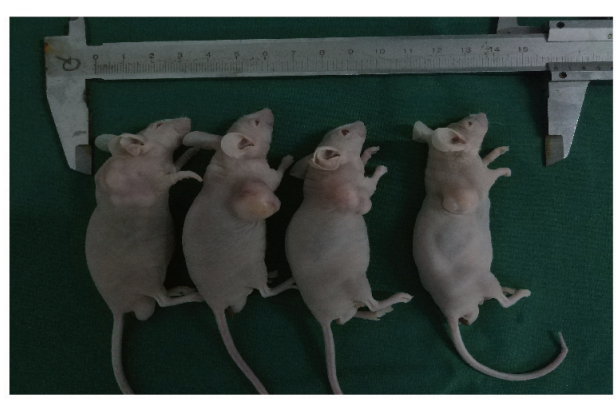

C

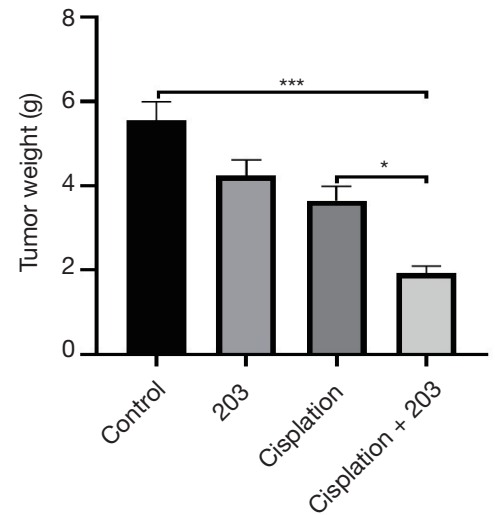

B

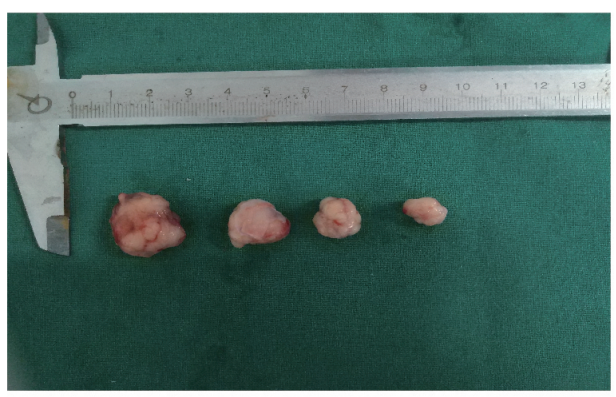

D

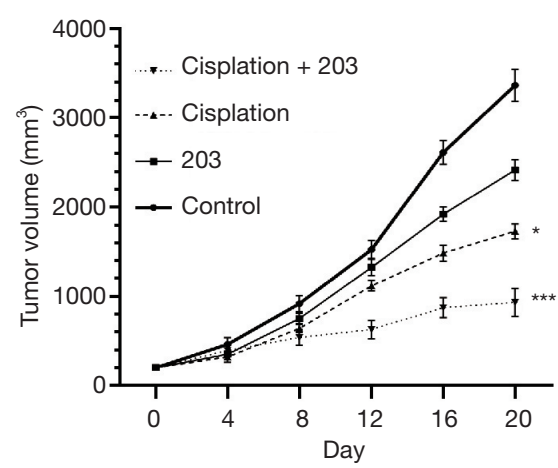

Figure 5 GO-203 treatment reversed the cisplatin resistance in mice. (A) BALB/c nude mice were injected subcutaneously with $1 \times 10^{7}$ Eca109/cDDP cells in their flank region. After confirmation of tumor development, mice were pair matched into four groups of five mice each and administered PBS (control vehicle), GO-203 (15 mg/kg), cisplatin $(15 \mathrm{mg} / \mathrm{kg}$ ) or $15 \mathrm{mg} / \mathrm{kg}$ cisplatin and $15 \mathrm{mg} / \mathrm{kg}$ GO-203 administered intraperitoneally daily for 20 days. (B,C,D) The results are expressed as tumor volume and weight (mean $\pm \mathrm{SD}) .\left(^{*}, \mathrm{P}<0.05\right.$; ${ }^{* * *}$, $\mathrm{P}<0.001)$. Control: the Eca109/cDDP cells treated with pure culture media; GO-203: a cell-penetrating peptide. PBS, phosphate-buffered saline; SD, standard deviation.

that targeting MUC1-C reversed the cisplatin resistance of Eca109/CDDP cells and promoted apoptosis. These observations were further confirmed by western blot analysis of apoptosis-related factors Bcl-2 and Bax. Bcl2 is involved in the cytotoxicity mediated by a variety of anticancer drugs, including cisplatin. Thus, we analyzed Bcl-2 and Bax expression in response to combination treatment with GO-203 and cisplatin and confirmed that the combination treatment not only downregulated the Bcl-2 level significantly in Eca109/CDDP cells but also increased the expression of Bax. Therefore, we infer that blocking MUC1-C may reverse the cisplatin resistance in Eca109/CDDP cells, and inhibit cell proliferation, migration, invasion, and apoptosis via regulating the Akt and ERK signaling pathways.

We further observed that GO-203-treated ESCC xenograft tumors showed slower growth in vivo. With 3 weeks of combination treatment with GO-203 + cisplatin, the volumes of xenograft tumors in nude mice were significantly smaller than the those in animals treated with monotherapy, or in their control counterparts. These results suggested that targeting MUC1-C led to an increase in the cisplatin sensitivity in ESCC.

Therefore, the overall outcome of our study indicates that targeting MUC1-C by GO-203 could reverse the cisplatin resistance of ESCC cells in vivo and in vitro.

Our study has some limitations. For instance, we used only one blocking agent for this study and did not elucidate the complete signaling pathways responsible for the observed outcome. Nevertheless, further validation studies such as MUC1-C overexpression and silencing using plasmids or virus-based vectors, small interfering RNA, or short hairpin RNAs, are warranted. As MUC1-C overexpression is associated with poor prognosis in many other tumors, including breast cancer and carcinomas $(9,37)$, we speculate that MUC1-C overexpression in ESCCs could be responsible for the poor prognosis and development of chemoresistance in these cancers as well. 


\section{Conclusions}

Our results showed that targeting MUC1-C can hinder the cellular proliferation, migration, invasion, and survival of cancer cells. MUC1-C can induce apoptosis and reverse the cisplatin resistance in human ESCC cells. Therefore, MUC1-C has the potential of being an ancillary therapeutic molecule for ESCC patients who develop chemoresistance and improve their prognosis.

\section{Acknowledgments}

We would like to thank the Department of Thoracic Surgery, Department of Pathology and Central Laboratory of the Provincial Hospital Affiliated to Shandong University for their support during the study.

Funding: This work was supported by grants from the Natural Science Foundation of Shandong Province (2014ZRB14125) and the Key R\&D Project of Shandong Province (2018GSF118123).

\section{Footnote}

Reporting Checklist: The authors have completed the ARRIVE reporting checklist. Available at http://dx.doi. org/10.21037/tcr-20-2495

Data Sharing Statement: Available at http://dx.doi. org/10.21037/tcr-20-2495

Conflicts of Interest: All authors have completed the ICMJE uniform disclosure form (available at http://dx.doi. org/10.21037/tcr-20-2495). The authors have no conflicts of interest to declare.

Ethical Statement: The authors are accountable for all aspects of the work in ensuring that questions related to the accuracy or integrity of any part of the work are appropriately investigated and resolved. This study was carried out in strict accordance with the recommendations by the Guide for the Chinese Ethics Review Committees. The protocol was approved by the Ethics Committee of Shandong Provincial Hospital Affiliated to Shandong University, and the committee's reference number is LCYJ:NO.2019-164. Animal experiments were performed under a project license (license number No. 2019-015) according to the Guidelines for the Care and Use of Laboratory Animals. All animal experiments were approved by the Animal Policy and Welfare Committee under of
Shandong Provincial Hospital Affiliated to Shandong University granted by the Veterinäramt des Kantons Zürich, Switzerland, in compliance with the Swiss Animal Protection Act (TSchG) and the Swiss Animal Protection Ordinance (TSchV).

Open Access Statement: This is an Open Access article distributed in accordance with the Creative Commons Attribution-NonCommercial-NoDerivs 4.0 International License (CC BY-NC-ND 4.0), which permits the noncommercial replication and distribution of the article with the strict proviso that no changes or edits are made and the original work is properly cited (including links to both the formal publication through the relevant DOI and the license). See: https://creativecommons.org/licenses/by-nc-nd/4.0/.

\section{References}

1. Bray F, Møller B. Predicting the future burden of cancer. Nat Rev Cancer 2006;6:63-74.

2. Chen $\mathrm{W}$, Zheng R, Baade PD, et al. Cancer statistics in China, 2015. CA Cancer J Clin 2016;66:115-32.

3. Sasaki Y, Kato K. Chemoradiotherapy for esophageal squamous cell cancer. Jpn J Clin Oncol 2016;46:805-10.

4. Lagergren J, Smyth E, Cunningham D, et al. Oesophageal cancer. Lancet 2017;390:2383-96.

5. Mariette C, Piessen G, Triboulet JP. Therapeutic strategies in oesophageal carcinoma: role of surgery and other modalities. Lancet Oncol 2007;8:545-53.

6. Nath S, Mukherjee P. MUC1: A multifaceted oncoprotein with a key role in cancer progression. Trends Mol Med 2014;20:332-42.

7. Ye Q, Yan Z, Liao X, et al. MUC1 induces metastasis in esophageal squamous cell carcinoma by upregulating matrix metalloproteinase 13. Lab Investig 2011;91:778-87.

8. Kufe DW. Mucins in cancer: Function, prognosis and therapy. Nat Rev Cancer 2009;9:874-85.

9. Rajabi H, Kufe D. MUC1-C oncoprotein integrates a program of EMT, epigenetic reprogramming and immune evasion in human carcinomas. Biochim Biophys Acta Rev Cancer 2017;1868:117-22.

10. Kufe DW. MUC1-C oncoprotein as a target in breast cancer: activation of signaling pathways and therapeutic approaches. Oncogene 2013;32:1073-81.

11. Huang L, Chen D, Liu D, et al. MUC1 oncoprotein blocks glycogen synthase kinase $3 \beta$-mediated phosphorylation and degradation of $\beta$-catenin. Cancer Res 2005;65:10413-22.

12. Leng $\mathrm{Y}$, Cao C, Ren J, et al. Nuclear import of the 
MUC1-C oncoprotein is mediated by nucleoporin Nup62. J Biol Chem 2007;282:19321-30.

13. Raina D, Ahmad R, Rajabi H, et al. Targeting cysteinemediated dimerization of the MUC1-C oncoprotein in human cancer cells. Int J Oncol 2012;40:1643-9.

14. Zhang L, Yang X, Li X, et al. Butein sensitizes HeLa cells to cisplatin through the AKT and ERK/p38 MAPK pathways by targeting FoxO3a. Int J Mol Med 2015;36:957-66.

15. Chen CH, Lu PJ, Chen YC, et al. FLJ10540-elicited cell transformation is through the activation of PI3-kinase/ AKT pathway. Oncogene 2007;26:4272-83.

16. Xin GS, Zhao YQ, Jiang B, et al. Inhibition of MUC1-C regulates metabolism by AKT pathway in esophageal squamous cell carcinoma. J Cell Physiol 2019;234:12019-28.

17. Jung K, Kang H, Mehra R. Targeting phosphoinositide 3-kinase (PI3K) in head and neck squamous cell carcinoma (HNSCC) Kyungsuk. Expert Opin Ther Targets 2018;19:795-805.

18. Gornowicz A, Bielawska A, Czarnomysy R, et al. The combined treatment with novel platinum(II) complex and anti-MUC1 increases apoptotic response in MDA-MB-231 breast cancer cells. Mol Cell Biochem 2015;408:103-13.

19. Tao C, Lin H, Chen S. The regulation of ERK and p-ERK expression by cisplatin and sorafenib in gastric cancer cells. Gene 2014;552:106-15.

20. Zhou P, Zhang R, Wang Y, et al. Cepharanthine hydrochloride reverses the $\mathrm{mdr} 1$ (P-glycoprotein)mediated esophageal squamous cell carcinoma cell cisplatin resistance through JNK and p53 signals. Oncotarget 2017;8:111144-60.

21. Xin Z, Song X, Jiang B, et al. Blocking FGFR4 exerts distinct anti-tumorigenic effects in esophageal squamous cell carcinoma. Thorac Cancer 2018;9:1687-98.

22. Xin Z, Xin G, Shi M, et al. Inhibition of MUC1-C entering nuclear suppresses MYC expression and attenuates malignant growth in esophageal squamous cell carcinoma. Onco Targets Ther 2018;11:4125-36.

23. Lordick F, Mariette C, Haustermans K, et al. Oesophageal cancer: ESMO clinical practice guidelines for diagnosis, treatment and follow-up. Ann Oncol 2016;27:v50-7.

24. Martin JC, Herbert BS, Hocevar BA. Disabled-2 downregulation promotes epithelial-to-mesenchymal transition. Br J Cancer 2010;103:1716-23.

25. Tanaka M, Kijima H, Shimada H, et al. Expression of podoplanin and vimentin is correlated with prognosis in esophageal squamous cell carcinoma. Mol Med Rep 2015;12:4029-36.

26. Bray F, Ferlay J, Soerjomataram I, et al. Global cancer statistics 2018: GLOBOCAN estimates of incidence and mortality worldwide for 36 cancers in 185 countries. CA Cancer J Clin 2018;68:394-424.

27. Shi M, Chen D, Yang D, et al. CCL21-CCR7 promotes the lymph node metastasis of esophageal squamous cell carcinoma by up-regulating MUC1. J Exp Clin Cancer Res 2015;34:149.

28. Raina D, Ahmad R, Joshi MD, et al. Direct targeting of the mucin 1 oncoprotein blocks survival and tumorigenicity of human breast carcinoma cells. Cancer Res 2009;69:5133-41.

29. Joshi MD, Ahmad R, Yin L, et al. MUC1 oncoprotein is a druggable target in human prostate cancer cells. Mol Cancer Ther 2009;8:3056-65.

30. Wu DW, Wu TC, Wu JY, et al. Phosphorylation of paxillin confers cisplatin resistance in non-small cell lung cancer via activating ERK-mediated Bcl-2 expression. Oncogene 2014;33:4385-95.

31. Yin L, Ahmad R, Kosugi M, et al. Terminal differentiation of chronic myelogenous leukemia cells is induced by targeting of the MUC1-C oncoprotein. Cancer Biol Ther 2010;10:483-91.

32. Engelman JA, Luo J, Cantley LC. The evolution of phosphatidylinositol 3-kinases as regulators of growth and metabolism. Nat Rev Genet 2006;7:606-19.

33. Vanhaesebroeck B, Stephens L, Hawkins P. PI3K signalling: the path to discovery and understanding. Nat Rev Mol Cell Biol 2012;13:195-203.

34. Neuman I, Cooke M, Lemiña NA, et al. 5-oxo-ETE activates migration of $\mathrm{H} 295 \mathrm{R}$ adrenocortical cells via MAPK and PKC pathways. Prostaglandins Other Lipid Mediat 2019;144:106346.

35. Yoshioka A, Miyata H, Doki Y, et al. The activation of Akt during preoperative chemotherapy for esophageal cancer correlates with poor prognosis. Oncol Rep 2008;19:1099-107.

36. Tasioudi KE, Saetta AA, Sakellariou S, et al. PERK activation in esophageal carcinomas: Clinicopathological associations. Pathol Res Pract 2012;208:398-404.

37. Raina D, Uchida Y, Kharbanda A, et al. Targeting the MUC1-C oncoprotein downregulates HER2 activation and abrogates trastuzumab resistance in breast cancer cells. Oncogene 2014;33:3422-31.

Cite this article as: Zhao YQ, Wu T, Wang LF, Yin B, Shi M, Jiang B, Gong-Sun X, Song XM, Liu XY. Targeting MUC1-C reverses the cisplatin resistance of esophageal squamous cell carcinoma in vitro and in vivo. Transl Cancer Res 2021;10(2):645655. doi: 10.21037/tcr-20-2495 